\title{
AC 2012-3128: DESIGN OPTIMIZATION PROBLEM IN A MATERIALS ENGINEERING COURSE
}

\section{Mr. Fredrick A. Nitterright, Pennsylvania State University, Erie}

Fred Nitterright is a lecturer in engineering at Penn State, Erie, the Behrend College. He received a A.A.S. in mechanical drafting and design in 1989 from Westmoreland County Community College, a B.S. in mechanical engineering technology in 1991 from Penn State, Erie, the Behrend College, and a M.S. in manufacturing systems engineering from the University of Pittsburgh in 1998. Nitterright is a member of the American Society for Engineering Education (ASEE). Nitterright began his career as a machinist at Elliott Support Services in Donora, Penn., in 1986. He was employed as a computer-aided draftsman at Powerex, Inc., a project engineering at Stanko Products, a Process Engineer at Ami-Doduco, Inc., and a Project Engineer and Team Leader at Classic Industries, Inc., in Latrobe, Penn. Nitterright's employment at Behrend commenced in 1999.

\section{Robert Michael, Pennsylvania State University, Behrend}

Robert J. Michael, P.E. and Senior Lecturer for the School of Engineering at Penn State, Behrend, obtained his B.S. degree from Akron University, where he graduated summa cum laude, and his M.S. degree from Case Western University. Michael is currently working towards his doctorate in mechanical and aerospace engineering at Case Western Reserve. He joined the faculty at Penn State, Behrend, in the fall of 1999 as a lecturer in the Mechanical Engineering Technology Department. Prior to his employment at Penn State, Behrend, Michael spent several years in industry, where he worked as an Industrial Product Designer and Aerospace Product Designer for LORD Corporation and General Manager for National Tool and Equipment. Courses taught include finite element analysis, material science, statics, strength of materials, materials lab, machine design, product design, production design, plastic design and $\mathrm{FE}$ analysis, and engineering graphics. Research interests include design and optimization of elastomer components, elastomeric fatigue properties, hyperelastic modeling of elastomers, failure analysis of elastomeric components, seismic analysis of storage racks, experimental testing, and characterization of materials and general machine design. As an Engineering Consultant, he provided consulting services to local industry. Services include elastomeric product design and analysis, machine design, finite element analysis, solid modeling, vibration analysis, and diagnostic testing. Michael holds several patents and has several patents pending primarily in the area of noise and vibration isolation products. He is a licensed Professional Engineer in the commonwealth of Pennsylvania. 


\section{Design Optimization Problem}

\section{in a Materials Engineering Course}

Introduction

Many applications in mechanical design require engineers to optimize the design of parts that have been in use for some time. This paper will discuss a design project that is given to senior Mechanical Engineering Technology students in an upper-level Materials Engineering course. The uniqueness of the project is that it not only requires the student to optimize the geometry of a part, but also to determine an optimal material such that a design index is maximized (the design objective). A high design index requires product stiffness and strength to be maximized at minimal weight so both material selection and geometry play important roles. A typical design approach taught to the students prior to enrolling in the course might have been to assume a material (steel) then use strength of material concepts to determine geometry to meet a strength or stiffness requirement with little regard to weight, cost, or optimization. The purpose of this design project is not only to utilize the above methods for determining ideal geometry but also to utilize Cambridge Engineering Selector (CES) software to determine the optimal material. In addition to discussing a specific example used in the design project, this paper will discuss the grading rubric, examples of work performed by students, student feedback, and how this project could be used in other courses to enhance the student's education.

\section{Problem Definition}

The student is to design and optimize the C-shaped link shown in Figure 1 for static loading. Figure 2 shows a 3D view of an optimized C-shaped link. The geometry of the link cannot exceed the package size defined in Figure 1. The goal is to determine geometry and material such that the link is as strong as possible, as stiff as possible, and as light as possible while not exceeding the space constraints. The objective in choosing a material is to optimize a number of metrics of performance in the product in which it is used. ${ }^{1}$ The student should present designs 
with three different families of materials: optimal composite design, optimal plastic design, and optimal metal design. NOTE, the geometry for these three cases should be similar! The design index, $\mathrm{D}$, that they are trying to maximize is as follows:

$D=\frac{K^{1 / 3} F_{y}^{1 / 2}}{W}$

Where: $\mathrm{Fy}=\max$ load for yield, $\mathrm{K}=$ stiffness of part, $\mathrm{W}=$ weight of part

Figure 1 -Design of C-clamp. The geometry must not exceed the black box and must clear the work piece as shown. Depth (into paper) 2" max

\section{Design Approach}

The selection of a material for a specific application is a thorough, lengthy and expensive process. Almost always, more than one material is suited to an application and the final selection is a compromise that brings some advantages as well as disadvantages. ${ }^{2}$ The student should start by optimizing either geometry or material selection. Students are to employ CES to select the optimal material. Patton states that when a designer selects a material, the designer should consider three basic Figure 2 requirements: service requirements, fabrication requirements, and 3D View of C-shaped link

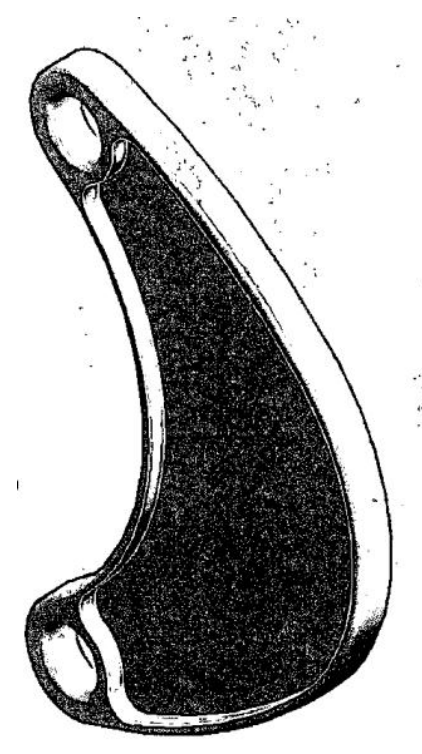


economic requirements. ${ }^{3}$ The C-clamp can be modeled as a cantilever beam with free height for the purposes of determining material performance indices. ${ }^{4}$ The appropriate material indices can be found in CES help files or lecture notes and are summarized below:

CES Approach for Material Selection:

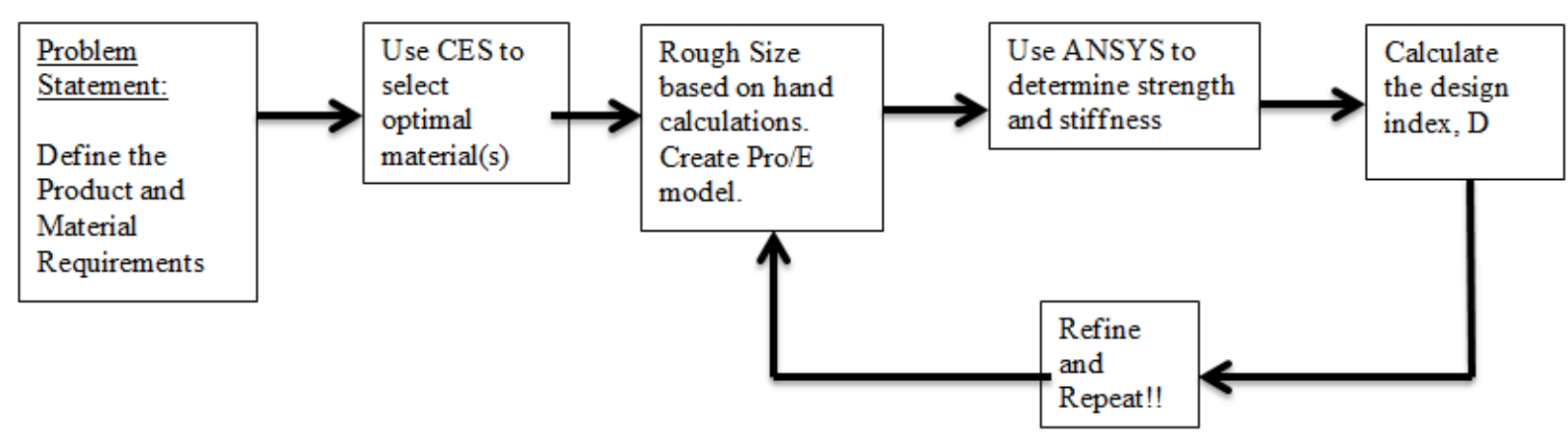

Stiffness constraint at minimal mass for beam with free height: $M_{1}=\frac{E^{1 / 3}}{\rho}$

Stiffness constraint at minimal mass for beam with free height: $M_{2}=\frac{\sigma_{y}{ }^{1 / 2}}{\rho}$

Students are required to find optimal material for three families of materials: composites, thermoplastics and metals. The CES approach is as follows:

1. Insert tree stage and add family of materials of interest (i.e. thermoplastics)

2. Insert a limit stage and filter out materials with percent elongation less than $5 \%$. This will eliminate brittle materials which are inappropriate for this application. Also, insert a maximum price of $\$ 100 / 1 b$ to eliminate any "exotic" materials.

3. Insert a graph stage of modulus vs density. Insert a line with slope $=3$.

4. Insert another graph stage of strength vs. density. Insert a line with slope $=2$.

5. Go back and forth between the two graph stages raising the line and filtering out materials. Continue to do this until there are 2-5 materials left. Select the "best" material - this will be the optimal material for this sample. Print out and save the material record. These are the properties used in the FE (finite element) analysis.

Geometry Approach 
Students should use basic strength of material concepts for curved beams to get some insight as to how the c-clamp should be designed. Then, create a design in Pro/E (Pro Engineer) and import it into ANSYS. In ANSYS, they apply a $1 \mathrm{lb}$ load to the inside surface of one hole and use a frictionless support at the inside surface of the other hole. Instead of frictionless support the student may also use a cylindrical support with radial and axial fixed and tangential free (note this is the same as frictionless support but more stable since the axial dof is eliminated). The yield load, Fy, can be determined by scaling the stress at $1 \mathrm{lb}$ to the yield stress then multiplying by $1 \mathrm{lb}$. The stiffness, $\mathrm{K}$, can be determined by taking $1 \mathrm{lb}$ divided by the average total deformation of the hole only at $1 \mathrm{lb}$. The student should continue to iterate in Pro/E and ANSYS until the student feels they have optimal geometry! The design index, D, should be calculated for each iteration and should be maximized as much as possible. This will help guarantee that the student has maximized the geometry as well as the material.

\section{Report Requirements}

Students work in groups of two and are required to submit a formal report. The report must contain the following:

1. Title Page - project title, instructor name, screen capture of the final design.

2. Table of contents w/ page numbers.

3. Introduction - clearly state the objective of the project (what it is they are trying to do). Briefly discuss the engineering tools used.

4. Summary - summarize important results only. Include the below table in the summary section:

\begin{tabular}{|c|c|c|c|c|c|c|c|c|c|c|c|}
\hline DESIGN & ITERATION & MATERIAL & $\begin{array}{c}\text { Yield Strength } \\
\text { (ksi) }\end{array}$ & $\begin{array}{c}\text { Modulus } \\
\text { (E6 psi) }\end{array}$ & $\begin{array}{l}\text { Density } \\
\text { (lb/in^3) }\end{array}$ & \begin{tabular}{|c|} 
Material \\
Index \\
M1 \\
\end{tabular} & \begin{tabular}{|c|} 
Material \\
Index \\
M2 \\
\end{tabular} & \begin{tabular}{|c} 
Stiffness, \\
$\mathrm{K}$ \\
(Ib/in) \\
\end{tabular} & \begin{tabular}{|c|} 
Yield \\
Load, Fy \\
(Ib) \\
\end{tabular} & $\begin{array}{c}\text { Weight } \\
\text { (Ib) }\end{array}$ & $\begin{array}{c}\text { Design Index } \\
\text { D }\end{array}$ \\
\hline \multicolumn{12}{|c|}{$\begin{array}{l}1 . \\
\text { Thermoplastic }\end{array}$} \\
\hline 2. Metal & $\begin{array}{l}1 \\
2\end{array}$ & & & & & & & $\begin{array}{l}64,672 \\
7,030\end{array}$ & $\begin{array}{l}7,405.80 \\
1.384 .80\end{array}$ & $\begin{array}{l}0.91695 \\
0.83372\end{array}$ & $\begin{array}{l}3765.755117 \\
854.789934\end{array}$ \\
\hline 3. Compos & & & & & & & & & & & \\
\hline
\end{tabular}

Table 1 - Summary of results for final designs of all three materials. 
5. Discussion - discuss results.

- What design is the best $(1,2$ or 3$)$ ? How did they select the optimal material? How did they optimize the geometry?

- The designs are strictly performance based but what if cost was an issue? How would the material selection change? The student should redo the CES part by replacing density with cost index (\$/lbs.) times density $\left(\mathrm{lbs} . / \mathrm{in}^{3}\right)$ which yields units of $\$ / \mathrm{in}^{3}$. This method allows students to rank materials based on a fixed volume associated with their design.

- The geometry for all three designs was the same which assumes that material selection has no impact on design. Is this entirely true? How might the designs change based on the material (hint: think contact stress with the plastic design, the $\mathrm{BC}$ applied does not consider this)? Are all materials isotropic? Large Deformation?

- The design of the c-clamp was really optimized for static loading. What if the loading was different (i.e. shock loading, fatigue loading, etc...) how would the approach differ? What additional material properties would be important? For static analysis, does the approach above capture every possible design issue which might impact material selection (hint: again think plastic!!)?

- The student is to add anything they feel is important. The student should do some independent research to verify material properties.

6. Appendix - include FE plots showing several iterations, including model refinement to determine optimal geometry. Include CES graph showing final materials left. Include material records for the three materials selected. Include hand calculations using curved beam theory for at least one case. The student should include a detailed, dimensioned drawing of the final design. Show isometric view, show section views as appropriate, follow dimensioning rules.

Grading Rubric

Below shows the grading rubric for the project paper.

- Cover Page ... 2.5 points

- Table of Contents ... 2.5 points

- Introduction ... 4 points

- Summary ... 20 points 
- Discussion/Technical Content ... 40 points

- Drawing ... 15 points

- Grammar/Spelling ... 7 points

- Format (Figures labeled properly, legible and easy to read page \#, etc.) .. 5 points

- Proper use of CES, hand calculations, and other courses to support claims/references ... 4 points

- Total ... 100 points

Student Feedback

At the completion of the project, the students were given a survey to gain insight on their thoughts about the project. There were 30 students that completed the survey. As with most student surveys, some student feedback was not helpful or not pertinent to this deisgn optimization problem so they were ommitted. The following shows the survey questions and a summation of the student's most often stated responses:

1. Which engineering course was the most beneficial to complete the project? The students responded that FE Analysis course and this Materials Engineering course were the most important.

2. What portion of the project challenged them the most? The students responded Pro/E modeling, finding the optimal design geometry, and stress analysis.

3. Rank the engineering topics mostly used (most to least):
a. FE Analysis
b. Design / Pro E
c. Material Science
d. Strength of Materials
e. Graphics / Drawing
f. Manufacturing

4. What did the student enjoy most? The students responded that they enjoyed the competition and freedom to make their own decisions with the design.

5. What did the student enjoy least? The students responded the the time involved with developing the report and nothing. 
6. What could be improved on the project to make a more valuable learning experience? The students responded again, nothing, and also to have the weight of the part be more important and more time to do the project.

Although not included as a survey question, students have verbally responded that the most important lesson learned from this Design Optimization Problem was the importance of material selection as well as the geometry. In other words, they understand that an optimal product includes both the optimal geometry and optimal material. Also, through many engineering deisgn iterations they come to realize that engineering a product in the real world is time consuming but the reward is greatly satisfying. Finally, they realize the importance of "engineering coupling" (i.e. how changing a part feature size may have a negative impact on weight but an overriding postitive impact on strength and stiffness).

\section{Use of this Project in Other Courses}

This project along with student results are used in other courses. For example, in Advanced Strength of Materials, curved beam theory is discussed and various student solutions are used to illustrate good (and poor) curved beam designs. Also, design optimization is discussed in a junior level Machine Design course to emphasize the importance of design iterations and brainstorming. Finally, the project is used in a senior level Finite Element Analysis course for Plastic Engineers. In this course, shape optimization analsyis (i.e. shape finder in ANSYS) is used to find the best use of a thermoplastic material for a body.

\section{Conclusions and ABET}

This design project clearly demonstrates the need for proper material selection, design iterations and refinement. Once the optimal materials are found, students typically iterate $20-30$ times changing geometry in Pro/E and importing this geometry into ANSYS for analysis to determine stress and stiffness. The student must calculate the performance (design) index for each of these design iterations. Students further refine the design to try to maximize this index. This project provides students with a strong foundation in design iterations and creates an atmosphere of friendly competition! The best student design had a design index, D, of 12,100 which resulted in 
first place for this student group. Finally, this design project has been used as a direct assessment tool for ABET accreditation for the following objectives:

Outcome A: The MET program must demonstrate that graduates have an appropriate mastery of the knowledge, techniques, skills, and modern tools of mechanical engineering technology

Sub-outcomes:

\begin{tabular}{|c|c|c|}
\hline a1 & $\begin{array}{l}\text { Mastery of knowledge current to } \\
\text { each student's year of study. }\end{array}$ & $\begin{array}{l}\text { Students are required to use high end } \\
\text { analysis tools (FEA) and verify stress } \\
\text { results with hand calculations. Curved } \\
\text { beam theory is used to calculate stresses } \\
\text { in c-clamp and compare these stresses to } \\
\text { ANSYS results. Von Mises stress and } \\
\text { various failure theories are used to make } \\
\text { sure safety requirements are met. } \\
\text { Students are required to use material } \\
\text { indices to maximize strength to weight } \\
\text { ratio and stiffness to weight ratio for } 3 \\
\text { classifications of materials: composite, } \\
\text { metal and thermoplastic. Finally, an } \\
\text { overall design index is calculated and } \\
\text { used as a means to benchmark and } \\
\text { optimize designs. An optimal design is } \\
\text { determined for all } 3 \text { families of materials: } \\
\text { metals, composite and thermoplastic. } \\
\text { Advanced graphics are used to produce a } \\
\text { detailed drawing for the final optimized } \\
\text { design. }\end{array}$ \\
\hline $\mathrm{a} 2$ & Mastery of techniques and skills & $\begin{array}{l}\text { This design project clearly demonstrates } \\
\text { the need for design iterations and } \\
\text { refinement. Students typically iterate } 20- \\
30 \text { times changing geometry in ProE and } \\
\text { importing into ANSYS for analysis. The } \\
\text { student must calculate the performance } \\
\text { (design) index for each design iteration. } \\
\text { Students further refine the design to } \\
\text { maximize the index. This project provides } \\
\text { students with a strong foundation in } \\
\text { design iterations. }\end{array}$ \\
\hline a3 & Mastery of modern tools & $\begin{array}{l}\text { Students are required to use CES } \\
\text { (material selection software by Granta) to } \\
\text { filter, screen, and rank and then select } \\
\text { optimal materials. Students are required } \\
\text { to use Pro/Engineer to create and modify } \\
\text { numerous designs. ProE is used to create }\end{array}$ \\
\hline
\end{tabular}




\begin{tabular}{|l|l|}
\hline & $\begin{array}{l}\text { detailed drawings. Students use an FEA } \\
\text { package, ANSYS to analyze their designs } \\
\text { for stress. Finally, students use } \\
\text { ShapeFinder function in ANSYS to } \\
\text { optimize their designs. }\end{array}$ \\
\hline
\end{tabular}

Summary \& Conclusions:

Class average score $84 \%$ exceeds Program target of $70 \%$

Conclusion: students exhibit the expected performance in mastery of the knowledge, techniques, skills, and modern tools of mechanical engineering technology.

Outcome B: The MET program must demonstrate that graduates have an ability to apply current knowledge and adapt to emerging applications of mathematics, science, engineering, and technology

Sub-outcomes:

\begin{tabular}{|c|c|c|}
\hline b3 & $\begin{array}{l}\text { Applications of engineering and } \\
\text { technology }\end{array}$ & $\begin{array}{l}\text { This project clearly captures the need for } \\
\text { students to adapt to emerging applications } \\
\text { of engineering. The latest engineering } \\
\text { software packages are used to complete } \\
\text { the project. A full search on latest } \\
\text { engineering materials is used in } \\
\text { conjunction with state of the art software } \\
\text { to find the "best" engineering material. } \\
\text { This material changes from year to year } \\
\text { due to advances in thermoplastics and } \\
\text { composites. }\end{array}$ \\
\hline
\end{tabular}

Summary \& Conclusions:

Class average score $84 \%$ exceeds Program target of $70 \%$

Conclusion: students exhibit the expected performance in applying current knowledge

and adapt to emerging applications of mathematics, science, engineering, and technology.

\section{Bibliography}

1. Multi-Criteria Material Selection in Engineering Design, Pasu Sirisalee, Michael F. Ashby, Geoffrey, T. Parks, and P. John Clarkson, Advanced Engineering Materials, 2004.

2. Material Considerations in product design: A survey on crucial material aspects used by product designers, Elvin Karana, Paul Hekkert, and Prabhu Kandachar, Materials and Design, Volume 29, pp. 1081-1089, 2008.

3. Materials in industry, Patton WJ, New Jersey, Prentice Hall, 1968. 
4. Materials, Engineering, Science, Processing and Design, M. Ashby, H. Shercliff, D. Cebon, Elsevier Ltd., 2007.

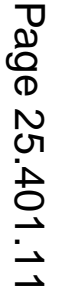

